
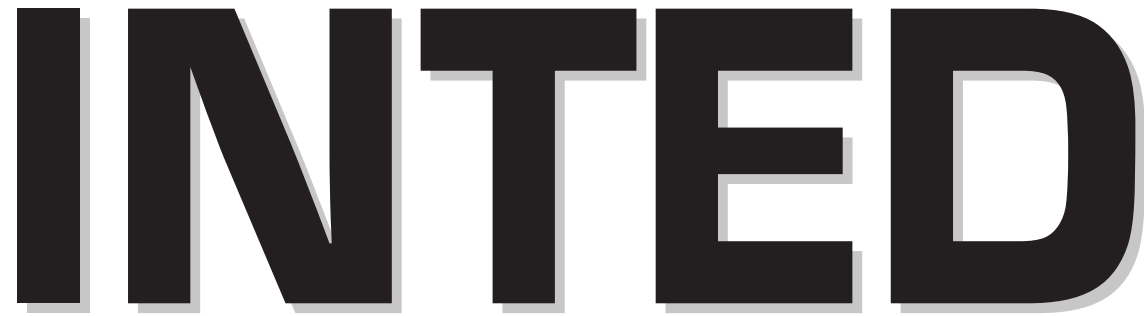

\section{7}

11th International

Technology, Education and

Development Conference

6-8 March, 2017

Valencia (Spain)

\section{CONFERENCE PROCEEDINGS}


Published by

IATED Academy

iated.org

INTED2017 Proceedings

11th International Technology, Education and Development Conference

March 6th-8th, 2017 - Valencia, Spain

\section{Edited by}

L. Gómez Chova, A. López Martínez, I. Candel Torres

IATED Academy

ISBN: 978-84-617-8491-2

ISSN: $2340-1079$

Depósito Legal: V-369-2017

Book cover designed by

J.L. Bernat

All rights reserved. Copyright (C) 2017, IATED

The papers published in these proceedings reflect the views only of the authors. The publisher cannot be held responsible for the validity or use of the information therein contained. 


\title{
CHANGE IN THE PERCEPTION OF MEDICAL STUDENTS ABOUT THE USEFULNESS AND IMPORTANCE OF SOCIAL MEDIA IN THEIR TRAINING AND THEIR FUTURE WORK AFTER RECEIVING A SPECIALIZED TRAINING COURSE
}

\author{
R. Reolid ${ }^{1}$, M. Galán de Juana ${ }^{2}$, J. Gonzalez-Rubio ${ }^{1}$, R. Ramirez-Vazquez ${ }^{1}$, P. \\ Gomez $^{1}$, C.P. Suarez-Rodriguez ${ }^{3}$, A. Beléndez ${ }^{4}$, E. Arribas ${ }^{1}$, F.J. Escobar- \\ Rabadan $^{5}$, A. Najera ${ }^{1}$ \\ ${ }^{1}$ University of Castilla - La Mancha (SPAIN) \\ ${ }^{2}$ Autonomous University of Madrid (SPAIN) \\ ${ }^{3}$ University of San Luis Potosi (MEXICO) \\ ${ }^{4}$ University of Alicante (SPAIN) \\ ${ }^{5}$ Health Center Zona IV. SESCAM (SPAIN)
}

\begin{abstract}
Social media can be an excellent tool in the training of future doctors, but also in their future work. For this, future health professionals should know basic concepts such as "personal brand" or know how to manage the privacy settings when sharing certain information in their personal profiles.

The aim of this study was to evaluate the changes in the perception and knowledge of medical students comparing the results of a survey before and after receiving a specialized training course. Issues such as whether they would be willing to put their personal accounts on their curriculum vitae or to hire erasure services in the network that minimize their fingerprint.
\end{abstract}

During the 2016-17 academic year a 2-hour course was taught by a sixth-year student and social networking expert. One week before the course and one month later an online survey of 16 questions was conducted and the results compared. The previous (pre) survey was answered by 107 students, while the post (post) survey was answered by 72 .

After the course, one of the first results was an increase in the number of students who knew social media specialized in Medicine. There are no significant changes in the way networks use, but there is an increase in the concern to publish reliable and proven medical information. An undesirable effect of the course is that there was an increase in the concern about a possible negative effect on their future of the information they share in social media, which can be positive because, despite this, there is an increase in the Number of students who would add their user on social media in their curriculum.

There is also an increase in the number of students who affirm that social media can be useful in their current training and in their future work, also in the knowledge of basic concepts as personal brand.

Keywords: Social media, personal branding, facebook, twitter, digital fingerprint

\section{INTRODUCTION}

Social media have revolutionized the way we connect and communicate to our society today. Its potential is beyond doubt and there are more and more areas that are betting on its applicability. The world of finance, medicine and teaching are some of the clearest examples [1].

Teens are a group very familiar with the use of social media and the field of teaching can benefit from it. The teaching model has for many years been anchored in a vertical master-pupil system where "master" classes and books have been the main learning tool. Without diminishing the importance they deserve, and after the arrival of new training models that are increasingly based on self-learning, the inclusion of new technologies led by social media in the teaching model of the 21 st century is required [2].

Learning by the students of medicine includes a series of aspects that deserve more attention. The use of social media by health professionals when it is time to publish or share certain information may not be the most adequate, sometimes surpassing the thin line that separates their personal life from the professional [3]-[5]. 
For this and other reasons, so far the majority of studies have focused on warning about the dangers and negative consequences of inappropriate use of social media by medical students [6]. These dangers are there, but the benefits of information technology and science should also be explored. Benefits that lead to multidirectional communication and learning taking advantage of the multiple interconnections offered by social media.

The aim of this study was to evaluate the changes in the perception and knowledge of medical students comparing the results of a survey before and after receiving a specialized training course.

\section{METHODOLOGY}

In October 2016, during the academic year 2016-2017, first-year medical students at the University of Castilla La Mancha in Albacete (UCLM) were invited to voluntarily answer, with prior informed consent, an online questionnaire on use of social media.

The questions were the following:

1 Indicate in which of the following social media you have user account and access frequency.

2 Indicate in which of the following messaging services you have a user account and the frequency of access.

3 Do you know any specific social media related to medicine?

4 For what purpose do you use social media?

5 Do you share information about medical topics on social media? For what purpose?

6 When you share medical information, do you check the reliability of the information?

7 Do you think that you have ever shared something that may have violated the confidentiality of a patient?

8 Do you think that sharing information can negatively affect the future of your career?

9 Would you feel comfortable putting your Facebook or Twitter username on your curriculum vitae?

10 Would you be willing to hire a service that eliminates from the Internet any content that could negatively affect your reputation?

11 Do you know the term of personal brand?

12 Do you think that social media can be useful in your training?

13 Do you think that social media can be useful in your future work?

14 Do you think that a course should be taught in the University about the correct use of social media by health professionals?

15 Do you think that there should be sanctions within the different work centers by those who make inappropriate use of social media?

In the following days, a sixth-year medical student specializing in the use and management of social media gave them a two-hour course on this subject at the Faculty of Medicine in Albacete.

Two weeks later, the students who had previously answered the question and attended the course, responded again online in order to measure the possible impact that could have the impact on their knowledge of social media.

\section{RESULTS}

The previous survey was answered by 107 students while the post survey was answered by 72 . The most common social media used by medicine students were Instagram $(78,5 \%)$, Twitter $(57 \%)$ and Facebook. (43,9\%). About instant messaging, Whatsapp (98.1\%) and Snapchat $(68.2 \%)$ were the most common. The main uses of social media were access to information $(33.2 \%)$, sharing $(29.4 \%)$ and gossip (28.4\%). There were no changes in the most used media or their uses after the expert's performance. 


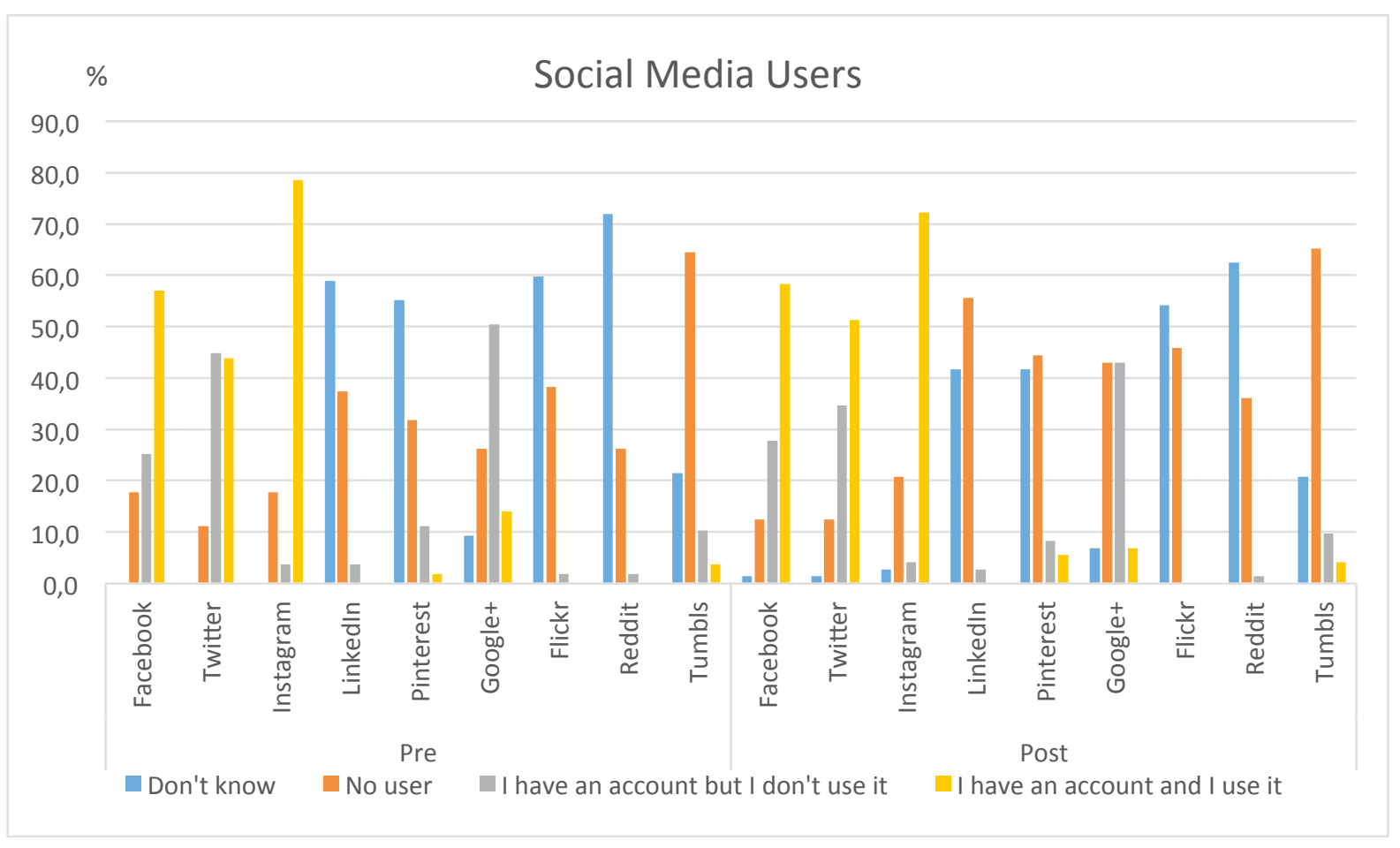

Fig 1. The most common social media used by medicine students

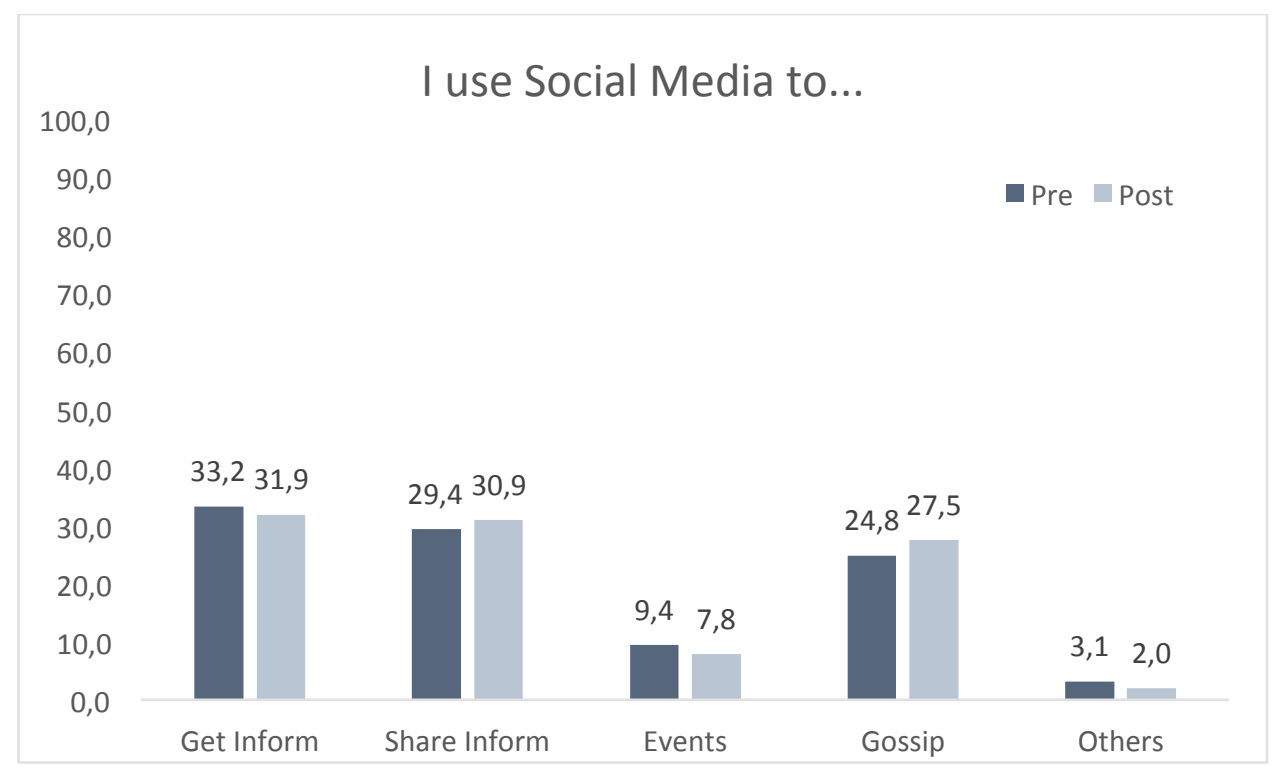

Fig 2. Social media uses

Before the course, only 4 students knew any of the specific social media of Medicine. We found an increase in the number of students who met social media specialized in Medicine in the post survey. 


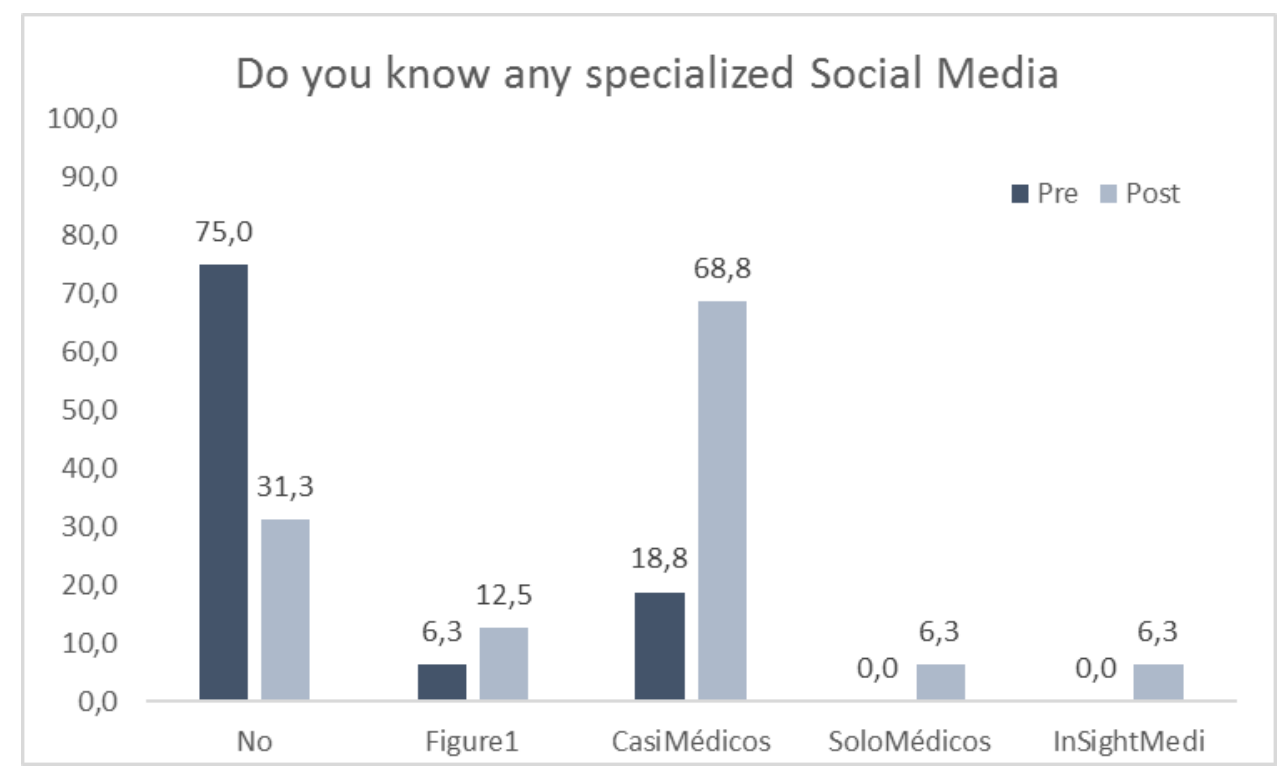

Fig 3. Specialized social media knew by medicine students.

72.9 percent had shared medical information on social media at least once, but more than a quarter of the students $(27.5 \%)$ didn't check the reliability of the information found in the Internet. This last percent decreases to $20 \%$ after the completion of the course.

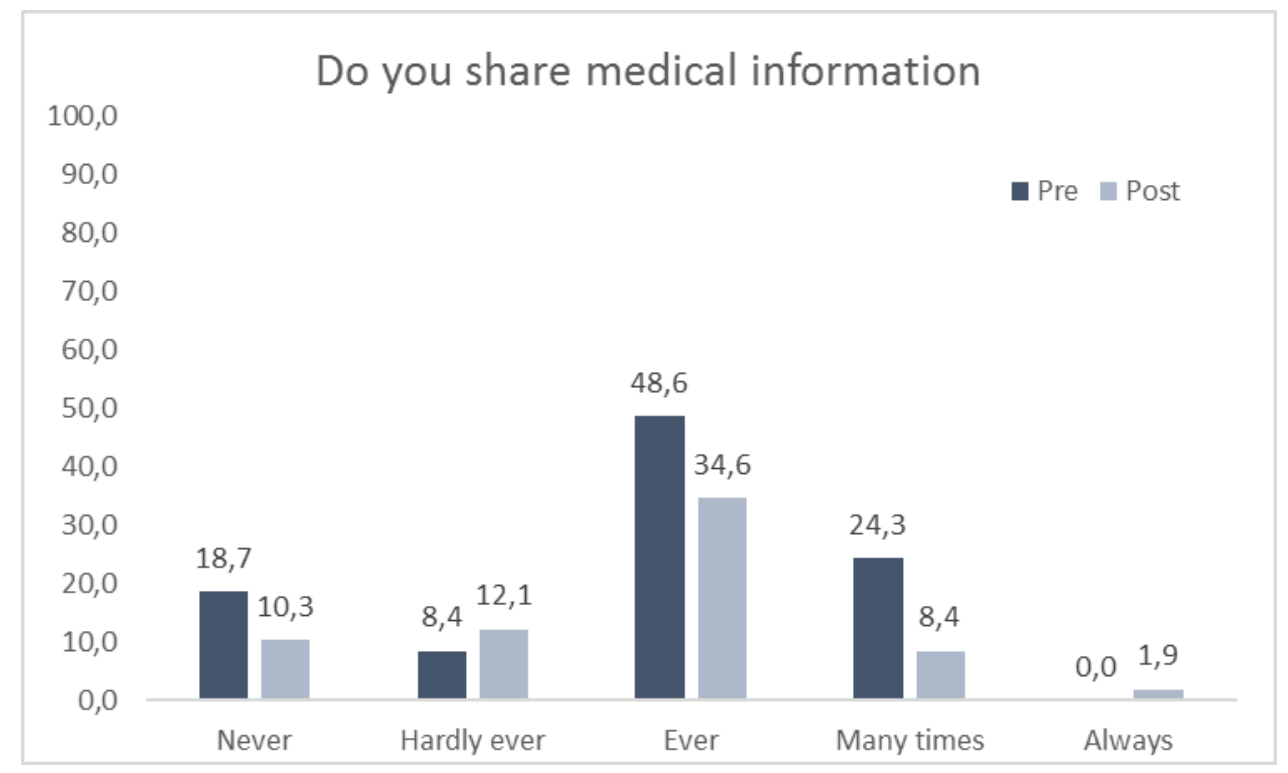

Fig 4. Percentage of medical students who share medical information.

In the previous survey, 50 percent of students thought that social media could negatively affect their professional future. They would be willing to hire a service that removes from the Internet information that could negatively affect them. There were no changes in the subsequent survey.

64,2 percent did not know the term personal brand. After the course, 98,6 percent knew the meaning of that term. 


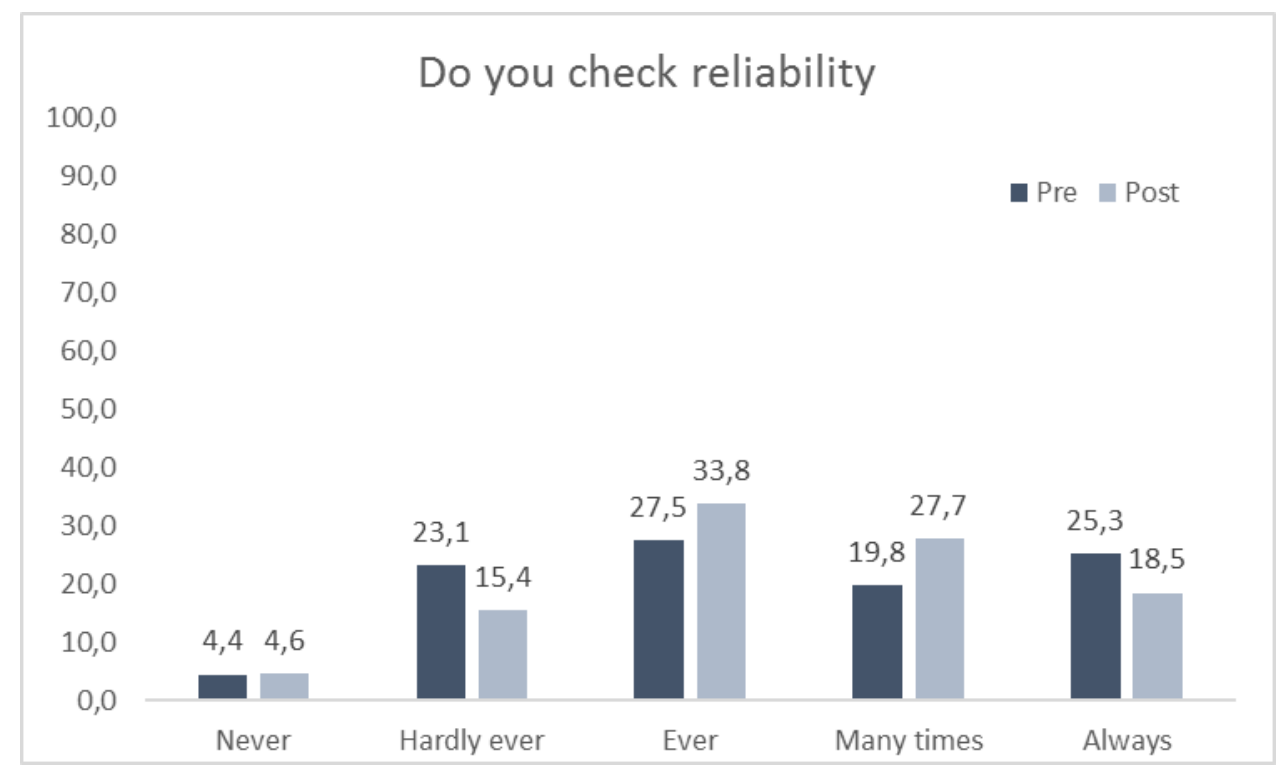

Fig 5. Percentage of medical students who test reliability found on the Internet

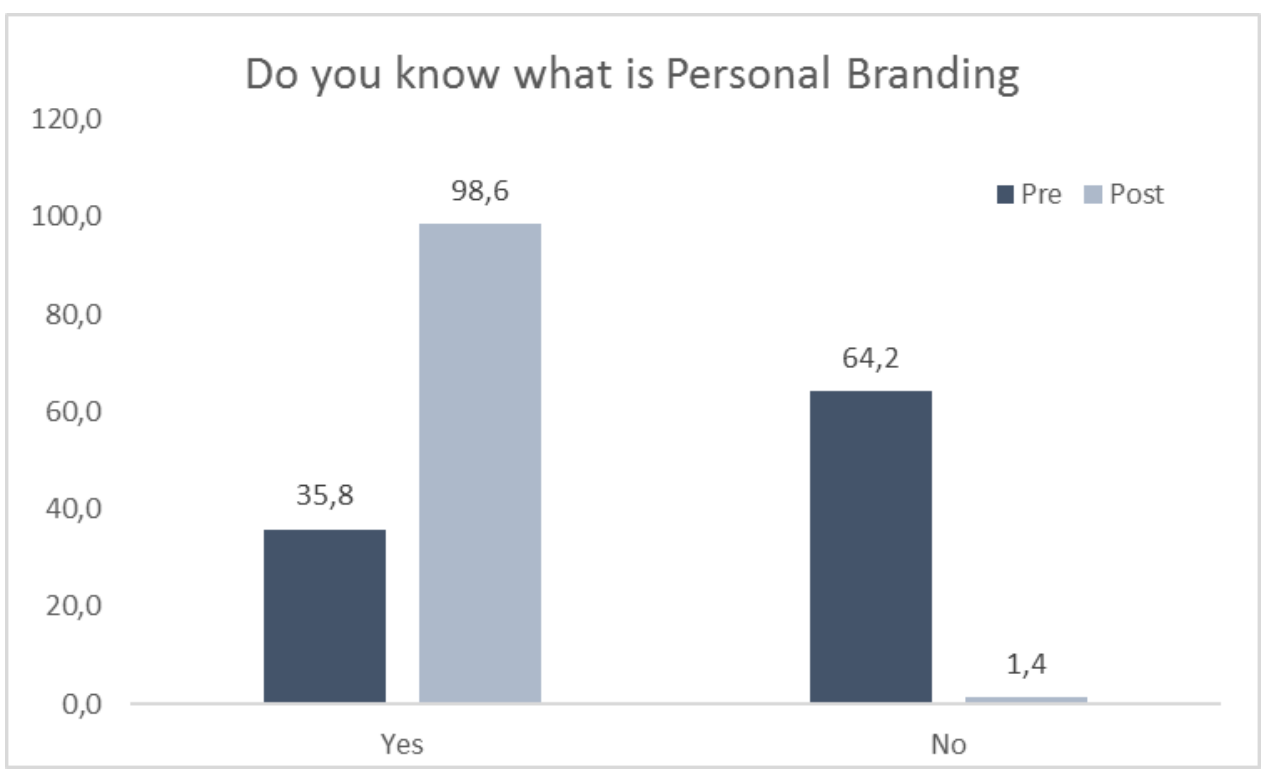

Fig 6. Number students knew Personal Branding term.

More than 85 percent believed that social media could be beneficial to both their training and their professional future. Most of the students thought that they should be trained in the University about the use of social media (77.1\%). These percentages were increased in the subsequent survey.

\section{DISCUSSION}

The benefit of social media as a support tool for the training of medical students, where the practical and audiovisual environment have an important role should be exploited [7].

Chretien et al. [8] described how Twitter has become a weapon to enhance student learning and foster intercommunication through user interconnection. Some authors already focus on the great potential of Twitter by developing guides for its use in order to make it one of the main tools within medical education [9]. Alsobayel et al. [10] also showed the trend towards greater use of social media by health professionals to solve daily problems of the consultation. 


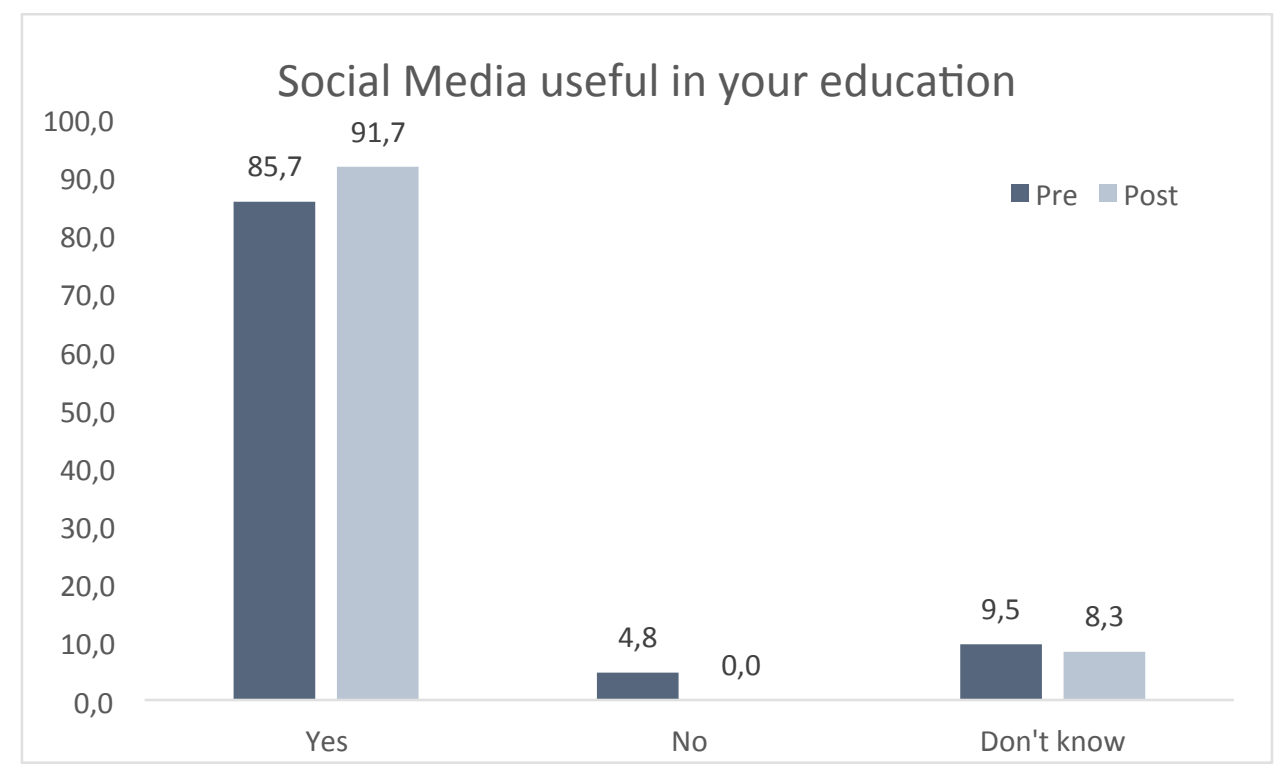

Fig 7. Percentage of medical students who consider social media useful in their education.

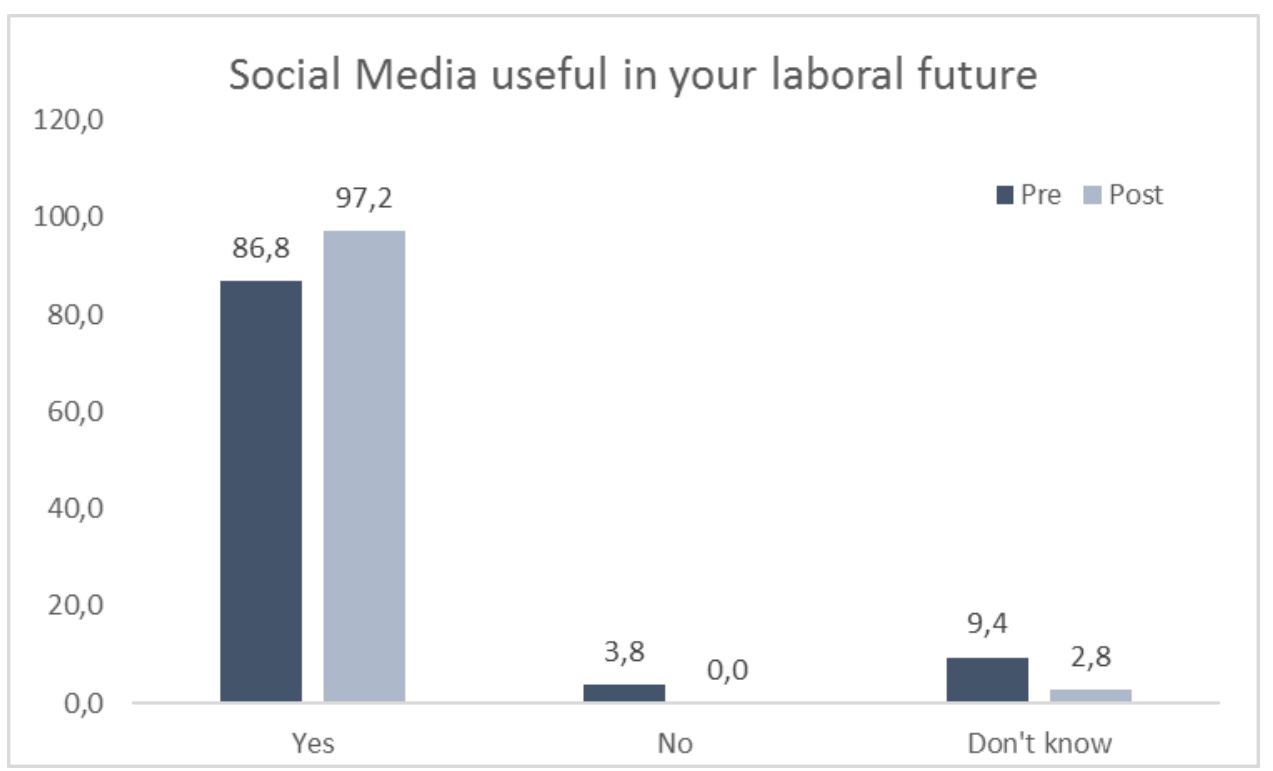

Fig 8. Percentage of medical students who consider social media useful in their laboral future.

Brisson et al. [11] analyzed the different behaviors that students present with respect to teachers when it comes to managing social media. The former tend to be more use of being tools, although sometimes they do not in the most appropriate way, which would force teachers to find ways to guide them to a correct use of them. They analyzed the use of social media by medical students searching what would be the main points that should cover such courses defining the main topics that should be addressed by the online presence, managing friend requests from patients, dealing with colleagues who post harmful content, Conducting Internet searches on patients, and discussing boundaries to identify potential harms associated with SNS usage.

Lie et al. [12] performed a similar intervention to this study in order to evaluate if the knowledge and attitudes of medical students can be modified after an intervention about the need for professionalism in social media. After this course, the students showed a greater capacity for analysis and awareness about what they publish in their social media.

Therefore, this study follows the line and reinforces the need to continue investigating not only how social media can be a more ally in the training of medical students, but also in how to create courses or guides that lead them to an appropriate use of the same. 
An example of how to guide students and residents of medicine in the proper use of social media would be the practice of the General Council of Official Physicians' Colleges with the development of their style manual for doctors and medical students [13].

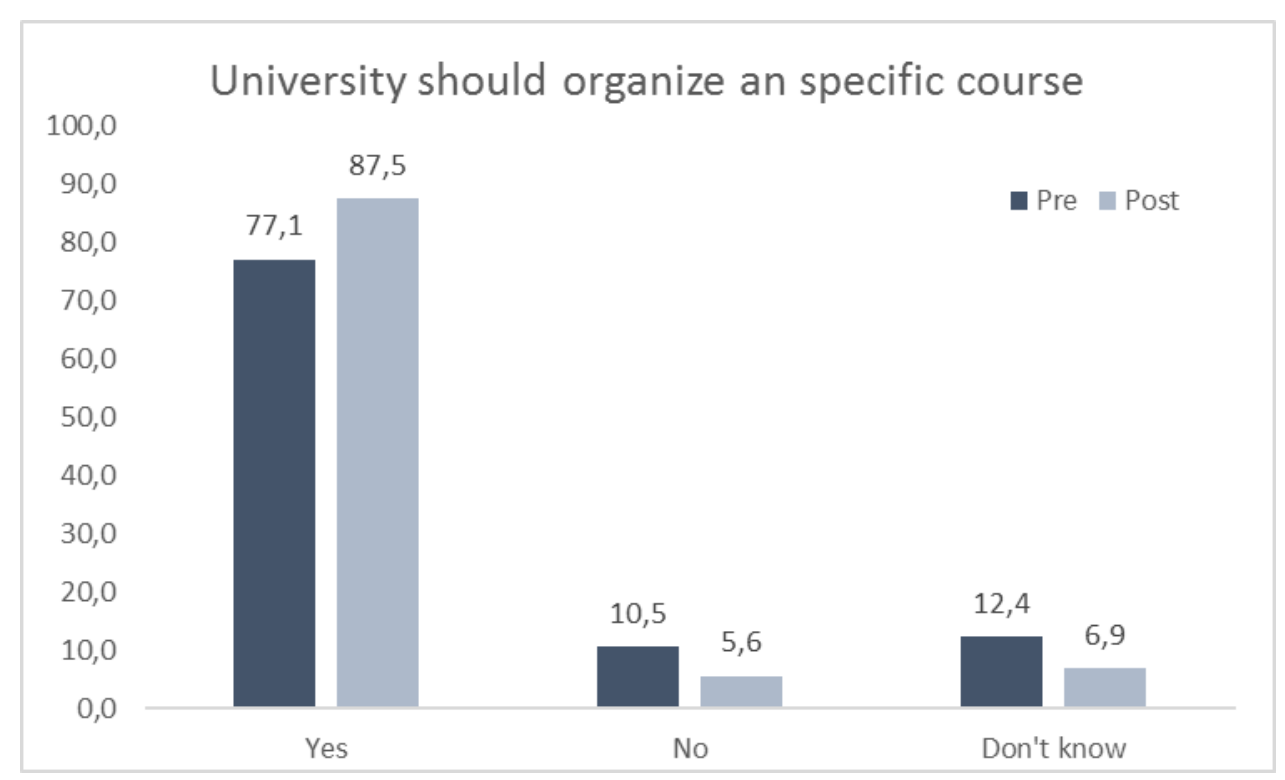

Fig 9. Percentage of medical students who consider that University should organize a specific course about social media.

According Mostaghimi et al. [14], within a digitized world where it is increasingly easier to access not only the information, but also the public profiles of people, health professionals should know how to organize their social media in order to maintain certain Levels of privacy that at the time of sharing information, respect the privacy of their patients and comply with medical professionalism.

\section{CONCLUSIONS}

Conducting specific training about the correct use of social media to medical students should be an objective to be developed by university teachers. This learning would allow to lay the foundations so that their students will make a correct use of them in order to avoid problems of malpractice and privacy, which in many cases they fail because they have not received a culture of the same.

Medical students should be aware that their behaviour should be in accordance with those of a health professional, with a series of obligations and ethical issues that they must know from the beginning of their learning in the hospital environment.

\section{ACKNOWLEDGEMENTS}

To the medical students who participated in this work and the Faculty of Medicine of the University of Castilla La Mancha.

\section{REFERENCES}

[1] K. Collins, D. Shiffman, y J. Rock, «How Are Scientists Using Social Media in the Workplace?», PloS One, vol. 11, n. ${ }^{\circ}$ 10, p. e0162680, 2016.

[2] S. El Bialy y A. Jalali, «Go Where the Students Are: A Comparison of the Use of Social Networking Sites Between Medical Students and Medical Educators», JMIR Med. Educ., vol. 1, n. ${ }^{\circ}$ 2, p. e7, sep. 2015.

[3] D. R. George y M. J. Green, «Beyond good and evil: exploring medical trainee use of social media», Teach. Learn. Med., vol. 24, n. ${ }^{\circ}$ 2, pp. 155-157, 2012.

[4] D. Patel y D. Jermacane, «Social media in travel medicine: a review», Travel Med. Infect. Dis., vol. 13, n. ${ }^{\circ}$ 2, pp. 135-142, abr. 2015. 
[5] K. N. Nason, H. Byrne, G. J. Nason, y B. O’Connell, «An assessment of professionalism on students' Facebook profiles», Eur. J. Dent. Educ. Off. J. Assoc. Dent. Educ. Eur., oct. 2016.

[6] K. C. Chretien, S. R. Greysen, J.-P. Chretien, y T. Kind, «Online posting of unprofessional content by medical students», JAMA, vol. 302, n. ${ }^{\circ} 12$, pp. 1309-1315, sep. 2009.

[7] J. M. Bernhardt, J. Alber, y R. S. Gold, «A social media primer for professionals: digital dos and don'ts», Health Promot. Pract., vol. 15, n. ${ }^{\circ}$ 2, pp. 168-172, mar. 2014.

[8] K. C. Chretien, M. G. Tuck, M. Simon, L. O. Singh, y T. Kind, «A Digital Ethnography of Medical Students who Use Twitter for Professional Development», J. Gen. Intern. Med., vol. 30, n. ${ }^{\circ} 11$, pp. 1673-1680, nov. 2015.

[9] S. E. Forgie, J. P. Duff, y S. Ross, «Twelve tips for using Twitter as a learning tool in medical education», Med. Teach., vol. 35, n. ${ }^{\circ}$ 1, pp. 8-14, 2013.

[10] H. Alsobayel, «Use of Social Media for Professional Development by Health Care Professionals: A Cross-Sectional Web-Based Survey», JMIR Med. Educ., vol. 2, n. ${ }^{\circ}$ 2, p. e15, sep. 2016.

[11] G. E. Brisson, M. J. Fisher, M. W. LaBelle, y S. E. Kozmic, «Defining a mismatch: differences in usage of social networking sites between medical students and the faculty who teach them», Teach. Learn. Med., vol. 27, n. ${ }^{\circ}$ 2, pp. 208-214, 2015.

[12] D. Lie, J. Trial, P. Schaff, R. Wallace, y D. Elliott, «"Being the best we can be”: medical students' reflections on physician responsibility in the social media era», Acad. Med. J. Assoc. Am. Med. Coll., vol. 88, n. ${ }^{\circ}$ 2, pp. 240-245, feb. 2013.

[13] «Etica y redes sociales 03.indd - Manual Redes Sociales OMC.pdf». http://www.cgcom.es/sites/default/files/u183/Manual\%20Redes\%20Sociales\%200MC.pdf .

[14] A. Mostaghimi y B. H. Crotty, «Professionalism in the Digital Age», Ann. Intern. Med., vol. 154, n. ${ }^{\circ}$ 8, p. 560, abr. 2011. 